\title{
Still another confounded face in the crowd
}

\author{
Dean G. Purcell \\ Oakland University, Rochester, Michigan \\ AND \\ Alan L. Stewart \\ Stevens Institute of Technology, Hoboken, New Jersey
}

\begin{abstract}
Experiments using schematic faces developed by Öhman (Öhman, Lundqvist, \& Esteves, 2001) seem to document an anger-superiority effect, although we have come to question these experiments. Our work shows that the low-level features of these schematic faces interact with the face's surround to produce effects that have been attributed to facial affect. Using relatively neutral faces that preserved the feature and surround spatial relationships of angry and happy schematic faces, we produced reaction times (RTs) that were indistinguishable from those found with angry and happy faces. We also found that the target face's position within the crowd determined the magnitude of the advantage for angry faces as well as for relatively affect-neutral faces. Removing the facial surround reduces the advantage for angry faces, largely by improving performance on happy faces. There was an apparent small advantage for angry features without a surround. Öhman faces avoid the problems associated with modified grayscale faces only to introduce an equally troubling confound.
\end{abstract}

An impressive number of studies claim angry expressions accelerate visual search for an angry face located within a crowd of happy or neutral faces (Eastwood, Smilek, \& Merikle, 2001; Fox et al., 2000; GilboaSchechtman, Foa, \& Amir, 1999; Lundqvist \& Öhman, 2005; Öhman, Lundqvist, \& Esteves, 2001; Schubö, Gendolla, Meinecke, \& Abele, 2006; Williams \& Mattingley, 2006). This finding is sometimes referred to as the anger-superiority effect (ASE), although angry faces are not always associated with superior performance. A briefly presented angry face retards identification of affect more than does a single happy face. This angerinferiority effect (AIE) occurs with grayscale faces (Boucher \& Carlson, 1980; Harrison, Gorelczenko, \& Cook, 1990; Juth, Lundqvist, Karlsson, \& Öhman, 2005, Experiment 4A; Kirouac \& Doré, 1984, 1985; Leppänen, Tenhunen, \& Hietanen, 2003; Mandal \& Palchoudhury, 1985; McAndrew, 1986; Pizzamiglio, Zoccolotti, Mammucari, \& Cesaroni, 1983; Purcell, Stewart, \& Skov, 1998; Shimoda, Argyle, \& Ricci-Bitti, 1978; Srivastava \& Mandal, 1990; Stalans \& Wedding, 1985; Wagner, MacDonald, \& Manstead, 1986). The AIE also occurs with schematic faces (Eastwood, Smilek, \& Merikle, 2003; Purcell \& Stewart, 2003). There is even evidence for an AIE in searches for an angry target face in a crowd of happy or neutral faces (Calvo \& Nummenmaa, 2008; Juth et al., 2005; Obrecht \& Purcell, 2005; Purcell, Stewart, \& Skov, 1996). This presents an antinomy in which angry faces both facilitate and impede visual search. That or the ASE is found only when a feature renders the angry face to be more conspicuous than the happy face (Calvo \& Nummenmaa, 2008).

A well-known example is the experiment of Hansen and Hansen (1988), in which digitized grayscale pictures of happy and angry faces were filtered to produce stark blackand-white representations. The filter's thresholding algorithm inadvertently produced a black splotch just beneath the chin of the angry female face and darkened the angry male face. Observers relied on these dark areas to guide them to the angry face. An AIE was found when the dark areas were removed (Purcell et al., 1996).

To avoid the peril associated with image processing of grayscale pictures, many investigators turned to schematic faces (Eastwood et al., 2001; Fox et al., 2000; Lundqvist \& Öhman, 2005; Öhman et al., 2001). We have come to believe that these schematic stimuli are also flawed because of the way in which low-level visual features represent anger and happiness. The lines representing the eyebrows and mouth of a schematic face interact with the surround representing the head (Calvo \& Nummenmaa, 2008; Coelho, Cloete, \& Wallis, 2010; Purcell \& Stewart, $2002,2005,2006)$. The resulting interplay of low-level visual elements - not the emotion represented by the lines - guides an observer's visual search.

\section{Rationale and Stimuli}

To explore the visual interaction of eyebrows and mouth with their surround, we used angry and happy schematic faces based on Öhman's stimuli (Öhman et al., 2001). We compared these faces with affect-neutral stimuli derived

D. G. Purcell, purcell@oakland.edu 
from Öhman's face stimuli. The Öhman faces are designed to be equally discriminable from a schematic neutral face, and they are (Lundqvist, Esteves, \& Öhman, 1999; Experiment 1 of the present article). Our affect-neutral stimuli are designed to keep the relationship between the facial surround and the facial features the same as that for Öhman faces, while minimizing their emotional impact (Experiment 1 of the present article). Our concern is with the visibility of the face when it is projected briefly to retinal points surrounding the macula, where acuity decreases rapidly. A glance at Figure 1 reveals a troublesome difference between angry and happy stimuli. For the happy face, the upturned mouth and the downturned eyebrows seem to conform to the ovoid surround of the head (we refer to these features as conforming/happy). For the angry face, the mouth's downward turned ends are directed at the head's surround. The upward-slanting eyebrows project toward the head's egg-shaped surround and are almost orthogonal to the surround (we refer to these features as nonconforming/angry).

Consider how the differences between these angry and happy faces play out as the stimuli are presented to different retinal locations. At the fovea, where resolution is best, happy and angry faces should be equally discriminable from neutral faces. Because the conforming/happy features are closer to the face's ovoid surround, however, placing a happy face away from the fovea, where acuity begins to decrease rapidly, causes the image to become less distinct. At these locations, the visual system creates a blurred image, causing the eyebrows and mouth of the happy faces to become indistinct from the contour of the surrounding ovoid, making it more difficult to discrimi- nate happy faces from neutral faces. This is less true for the nonconforming/angry faces. Because the angry features do not conform to the facial surround, the blurring that occurs at eccentric retinal locations does not cause angry features to blend into the facial surround as readily as it does with conforming/happy features. Consequently, nonconforming/angry features are more conspicuous than are conforming/happy features when they are presented farther from the fovea.

The less conspicuous the conforming/happy features, the more difficult it is to locate a happy face (Öhman et al., 2001, Experiment 2). Reaction times (RTs) are faster for a $2 \times 2$ array of faces (subtending $7 \times 7$ degrees of visual angle) than for a $5 \times 5$ array (subtending $19 \times 20.5$ degrees of visual angle). For the larger array, the time to locate a happy face is slowed, and misses increase. RTs to faces increase with increasing retinal eccentricity, if the size of the face is not increased to compensate for its more eccentric location (Rousselet, Husk, Bennett, \& Sekuler, 2005). For the $2 \times 2$ displays used by Öhman et al. (2001), the stimuli above and below fixation would have to be increased in size by a factor of 2.02; whereas, to be equally visible, stimuli directly left and right of fixation would have to be increased in size by a factor of 1.95. Stimuli on the corners of the display would have to be increased by a factor of 2.4. For Öhman's $5 \times 5$ displays, these factors would be 3.79 , 3.59 , and 4.81 , respectively.

Our view is that both angry and happy faces become more and more blurred with each increase of retinal eccentricity, but that there is a disproportionate loss of legibility for a happy face as its conforming features are blurred

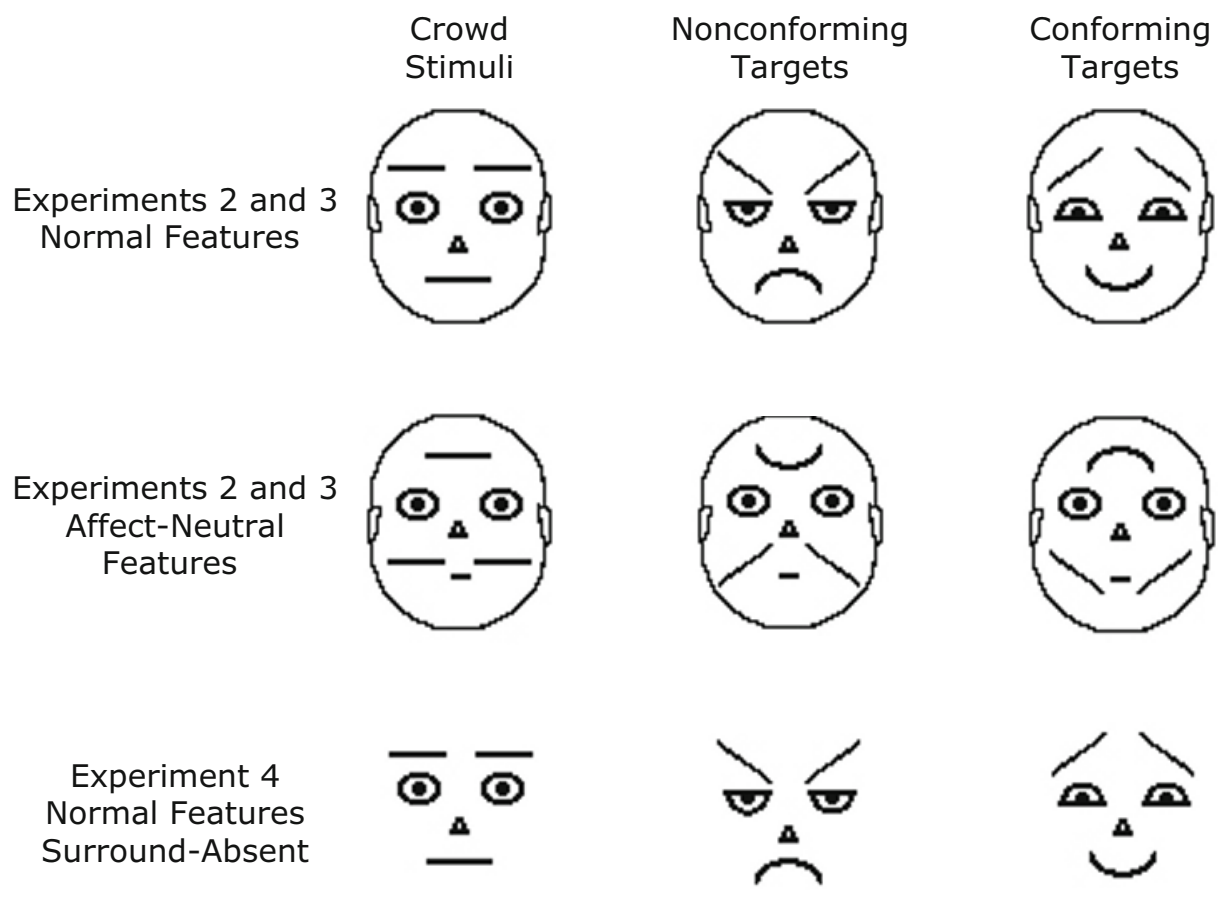

Figure 1. In Experiments 1A and 1B, these faces were rated for the degree to which they represent happiness or anger. 
with the head's surround. We believe that it is the disproportionate blurring of its features - not the differences in emotion conveyed by the visual features - that causes a happy face to be differentiated from the neutral distractors less quickly than an angry face. Three predictions are consistent with this argument. First, search times should increase if happy and angry faces are presented farther and farther from the fovea. Second, faces with conforming features should be at a disadvantage when compared with those having nonconforming features, even when these altered faces are judged to be relatively affect neutral (see Figure 1). The greatest disadvantage for the conforming/ happy face should occur at positions farthest from fixation. In short, the ASE results from that fact that it is more difficult to search for a conforming happy face than it is to search for a nonconforming angry face.

The third prediction is even more direct. Removing the facial surround allows the otherwise conforming features to become distinct elements that are no more susceptible to the effects of blurring than are the nonconforming features of the angry face. The RTs to happy and angry faces should become similar to the extent that an ASE is produced by facial features interacting with their surround, and the evidence for an ASE should melt away. Although we focus on the specific schematic faces employed by Öhman et al. (2001), it would be surprising if our analysis did not apply to various other schematic faces used in crowd-search experiments (e.g., Eastwood et al., 2001; Fox et al., 2000; Horstmann, 2007; Horstmann \& Becker, 2008; Tipples, Atkinson, \& Young, 2002).

\section{EXPERIMENT 1A Affect Rating}

Any discussion of affect and search begins with how well a stimulus face represents an emotion. An ASE requires that fast search times are associated with angry faces, whereas a pseudo-ASE is associated with nonconforming features that are not taken together as an angry face. Each of our stimuli, therefore, was rated on how happy or angry they seemed.

\section{Method}

Participants. Thirty-three undergraduates volunteered to serve as raters as part of their introductory psychology course. Participants provided informed consent, as is required by the Institutional Review Board of Oakland University. Two raters were dropped from the data analysis, because their ratings indicated that they reversed the rating scale.

Apparatus and Stimuli. Each of the nine individual faces used in Experiments 2-4 was centered on an $8.5 \times 11$ in. sheet of paper. Each face subtended $1.5 \mathrm{~cm}$ wide $\times 2.76 \mathrm{~cm}$ high. The numbers $1-10$ were printed at the top of each stimulus sheet. The phrase "Very Happy" was printed to the left of the numeral 1, and the phrase "Very Angry" was printed to the right of the numeral 10. A $25-\mathrm{cm}$ line represented the rating scale, with the numbers $1-10$ spaced evenly on the line. These nine rating sheets were assembled into stacks that were randomly ordered for each rater.

Procedure. Raters were given a stack of nine rating sheets and the following instructions: "You will be looking at line drawings of different faces that will range from happy to angry. We want you to rate them as to how they appear. Your task is to judge the expressions on these faces by circling the number at the top of the page that you feel most closely represents the displayed expression.” Ratings were self-paced.

\section{Results and Discussion}

We conducted individual analyses on each of the three face types (Öhman feature, affect-neutral, surroundabsent Öhman feature) used in each of the three visual search experiments. Figure 2 shows the affect ratings for the three types of stimuli.

The affect-neutral faces of Experiments 2 and 3 gave a small main effect of feature conformation $[F(2,60)=$ $\left.3.56, M S_{\mathrm{e}}=1.52, p=.035, \eta_{\mathrm{p}}^{2}=.11\right]$, with the nonconforming stimulus rated as 0.8 scale units angrier than was the conforming stimulus (see Figure 2). Post hoc tests (Bonferroni corrected) showed the small rating difference between conforming and nonconforming faces to be statistically significant ( $p=.04, r^{2}=.09$ ), with the nonconforming faces rated as being more angry (5.8) than were the conforming faces (5.0). The stimulus used as a distractor in Experiments 2 and 3 was rated at 5.24. This rating did not differ statistically from the ratings for the conforming stimulus ( $\left.p=.88, r^{2}=.007\right)$, nor did it differ from the ratings for the nonconforming stimulus ( $p=$ $\left..17, r^{2}=.056\right)$.

The Öhman-feature faces of Experiments 2 and 3 produced much larger rating differences $[F(2,60)=340.07$, $\left.M S_{\mathrm{e}}=0.985, p \leq .0001, \eta_{\mathrm{p}}^{2}=.92\right]$. Post hoc tests (Bonferroni corrected) showed a large (6.5 scale units) and a statistically significant difference between the nonconforming (9.26) and the conforming (2.73) stimuli $\left(p \leq .0001, r^{2}=\right.$ .92 ). Unlike our affect-neutral stimuli, both the conforming and nonconforming stimuli were rated as being significantly different from the distractor (5.34) stimulus ( $p \leq$ $.0001, r^{2}=.64$, and $p \leq .0001, r^{2}=.89$, respectively).

As with normal Öhman-feature faces, the surroundabsent stimuli used in Experiment 4 produced large rating differences, with the angry face rated 6.27 scale units more angry than was the happy face $[F(2,60)=299.20$, $\left.M S_{\mathrm{e}}=1.03, p \leq .0001, \eta_{\mathrm{p}}^{2}=.91\right]$. Post hoc tests (Bonferroni corrected) showed this large difference between the nonconforming (9.11) and the conforming (2.84) stimuli to be statistically significant ( $p \leq .0001, r^{2}=.92$ ). As with the normal stimuli of Experiments 2 and 3, both the conforming and nonconforming stimuli were rated as being significantly different from the distractor (5.55) stimulus $\left(p \leq .0001, r^{2}=.65\right.$, and $p \leq .0001, r^{2}=.76$, respectively).

\section{EXPERIMENT 1B Rating Affect-Neutral Faces Only}

In Experiment 1A, the ratings of three affect-neutral faces differed little, whereas the Öhman-feature faces were rated as being very different, even those with no surround. It is possible that, if affect-neutral faces were rated by themselves, they would have been rated as much different from each other, similar to the rating differences seen with Öhman-feature faces. A second rating experiment was conducted to determine whether rating differences between the conforming and nonconforming affect-neutral 


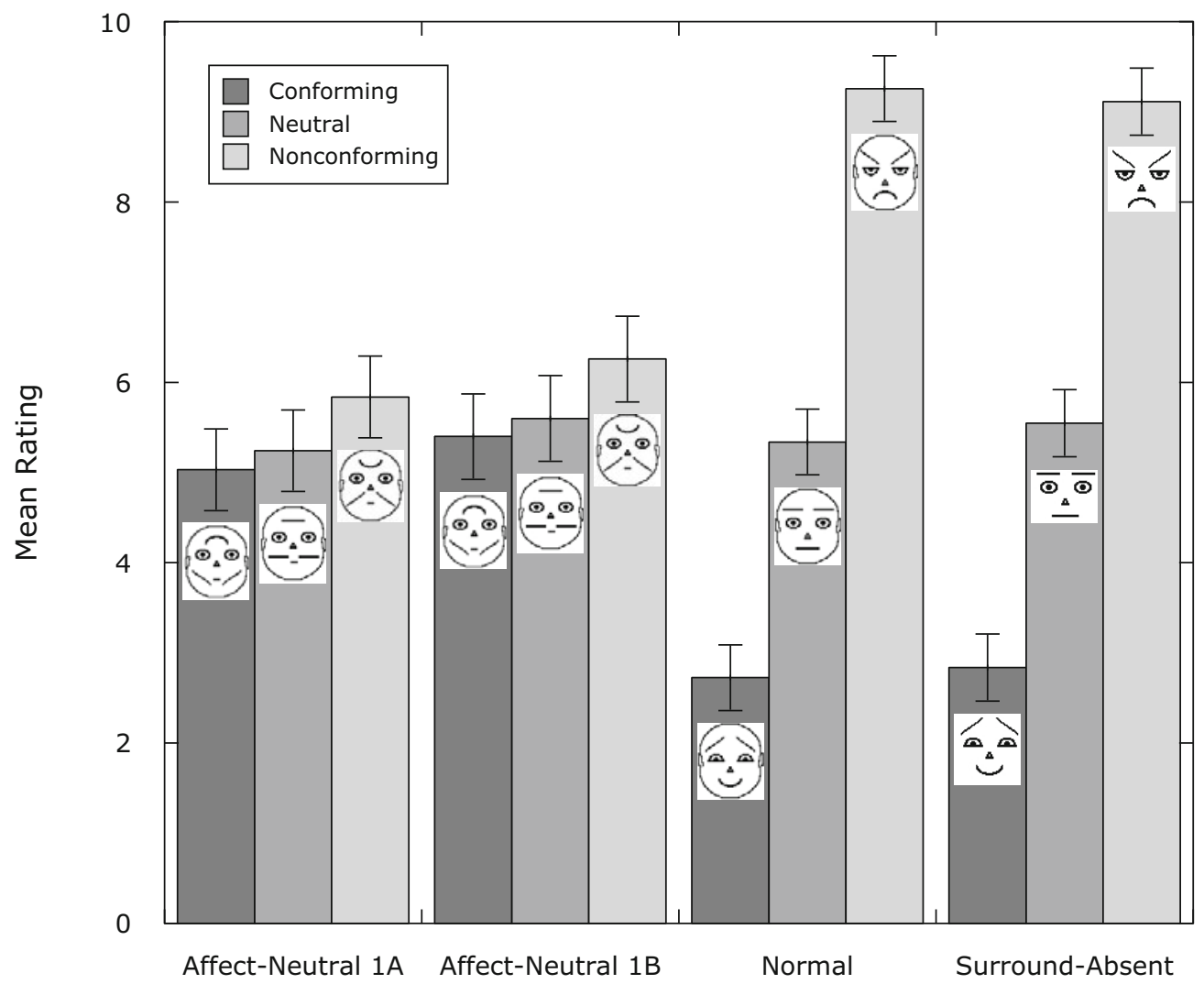

Stimulus

Figure 2. Shown are rating scores and $95 \%$ confidence intervals from Experiments $1 \mathrm{~A}$ and $1 \mathrm{~B}$. These ratings are for the target stimuli (conforming/happy, nonconforming/angry) and the crowd stimuli (neutral) of Experiments 2 and 3 (affect-neutral and normal) and for the stimuli (surround-absent faces) of Experiment 4 . The $95 \%$ confidence interval is based on the $M S_{\mathrm{e}}$ for feature conformation.

stimuli were compressed by being included with the more extremely rated angry and happy Öhman-feature faces.

\section{Method}

Participants. Forty-four undergraduates volunteered to serve as raters as part of their introductory psychology course. Participants provided informed consent, as is required by the Institutional Review Board of Oakland University.

Apparatus and Stimuli. The three individual affect-neutral faces used in Experiments 2 and 3 were projected on a screen, one at a time. Raters were given response sheets with four rows of the numbers $1-10$ printed at the top of each sheet. Descriptors anchored each end of the rating scale. Each row corresponded to the following stimulus dimensions: faceness (very un-face-like to very face-like), pleasantness (very pleasant to very unpleasant), activity (very passive to very active), and affect (very happy to very angry). These categories have been used in previous research (Lundqvist et al., 1999; Tipples et al., 2002). We wanted to see how affect judgments with our affect-neutral stimuli correlated with them.

Procedure. Raters were run in three separate groups, with each group seeing the three stimuli in a different random order. Raters were given a set of rating sheets and the following instructions: "You will be looking at line drawings of different stimuli. We want you to rate them as to how they appear along the four dimensions on your response sheets. Your task is to judge these stimuli by circling the number in each row that you feel most closely describes the displayed stimulus."

\section{Results and Discussion}

The results of Experiment 1B were identical to the affect-neutral stimulus results of Experiment 1A. The affect-neutral faces of Experiments 2 and 3 gave a statistically significant effect of feature conformation $\left[F(2,86)=3.68, M S_{\mathrm{e}}=2.44, p=.029, \eta_{\mathrm{p}}^{2}=.08\right]$; see Figure 2. Post hoc tests (Bonferroni corrected) showed that the small rating difference ( 0.86 scale points) between conforming and nonconforming faces was statistically significant $\left(p=.03, r^{2}=.07\right)$, with the nonconforming faces rated as appearing slightly more angry (6.26) than the conforming faces (5.39). These findings are identical with those of Experiment 1 with affectneutral stimuli. The stimulus used as the distractor in Experiments 2 and 3 for our affect-neutral faces was rated at 5.6. This rating did not differ statistically from those for the conforming stimulus ( $\left.p=.90, r^{2}=.004\right)$, nor did it differ from those for the nonconforming stimulus ( $p=$ $\left..14, r^{2}=.044\right)$.

Affect ratings were correlated with ratings for faceness, pleasantness, and activity. As we expected, the correlation of affect with pleasantness was statistically significant $(r=.52, p \leq .0001)$, and the more angry a face was rated, the more unpleasant it was judged. The correlation of af- 
fect with activity was also statistically significant $(r=$ $.27, p=.008)$, and the more angry a face was judged, the more active it was judged. Faceness did not correlate with $\operatorname{affect}(r=.003, p=.98)$.

According to Öhman et al. (2001), the more angry a face is judged to be, the faster an observer responds to it. If they are correct, the ratings generated in Experiments 1A and $1 \mathrm{~B}$ will predict an RT advantage for faces rated as angry over faces rated either as less angry or as happy. As is shown in the following experiments, this prediction is supported only partially: Affect ratings do not predict the magnitude of the ASE for our affect-neutral stimuli, nor do they predict the magnitude for surround-absent stimuli. The following search experiments demonstrate that differences in how angry a face appears are strongly correlated only with RTs for Öhman-feature faces with surrounds. The correlation breaks down for affect-neutral faces and for surround-absent faces.

\section{EXPERIMENT 2 \\ A Variation of Öhman et al. (2001)}

We set out to produce a pseudo-ASE - that is, a perceptual advantage for the lines used to draw a face rather than the emotion that the features signal. Our first experiment was designed to demonstrate that faces with nonconforming features are located more quickly than are those with conforming features, even when the features represent neither anger nor happiness. Our experimental manipulation placed both the outgoing and conforming eyebrows and mouths so that they no longer produced happy or angry expressions, yet still produced two distinctly different target stimuli: one with conforming features and one with nonconforming features. We compared these affectneutral stimuli with faces used in the Öhman et al. (2001) experiments. The affect-neutral condition was designed to demonstrate two things: That relatively neutral stimuli with nonconforming features are located as quickly as Öhman-feature angry faces are and that relatively neutral stimuli with conforming features are just as perceptually disadvantaged as are Öhman-feature happy faces. Both the affect-neutral and Öhman-feature stimuli can be seen in Figure 1.

We treated feature conformation (conforming/happy vs. nonconforming/angry) and retinal position as withinobserver variables. Nonconforming/angry features were compared with conforming/happy features across nine retinal positions. Feature organization is a between-observer variable with two levels: Öhman features derived from the Öhman et al. (2001) stimuli are compared with our affectneutral target stimuli (see Figure 1).

Observers were told to look at a briefly flashed array of faces. They were told that, if an array contained a face that differed from the other faces in the array, they were to press a response key; otherwise, they were to make no response. The retinal position of stimuli was varied to determine whether search times and the ASE increase for stimuli presented farther from the fovea. Our conforming and nonconforming stimuli were presented in a $3 \times 3$ matrix of faces, as is shown in Figure 3.

\section{Method}

Participants. Thirty-four undergraduates volunteered to serve as observers as part of their introductory psychology course. Participants provided informed consent, as is required by the Institutional Review Board of Oakland University. Seventeen observers were used in the affect-neutral condition and 17 different observers were
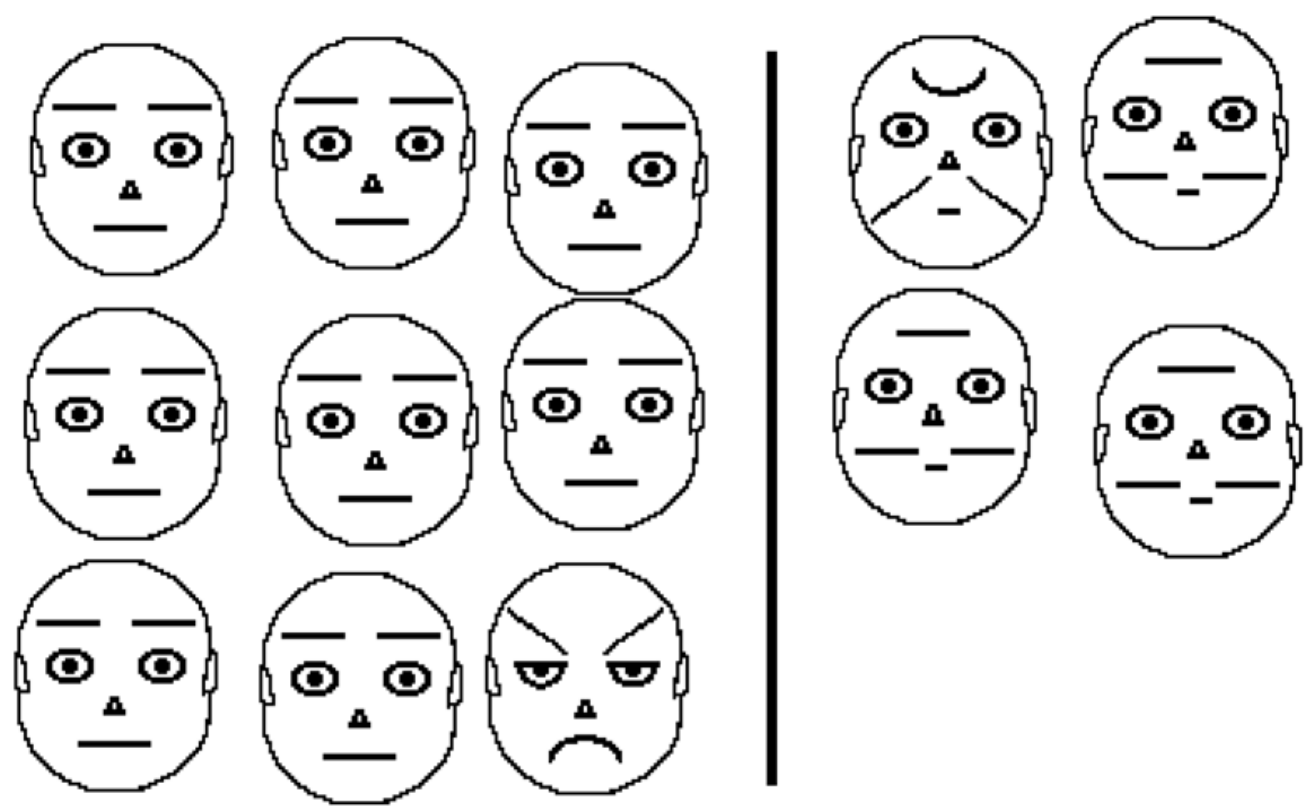

Figure 3. Two examples of the stimulus arrays used in Experiments 2 and 3. Shown is the typical trialto-trial random jitter. On the left is a nine-item display showing Öhman-feature stimuli. On the right is a typical affect-neutral four-item display used in Experiment 3. Note that, when four items are presented, the distractors have the same proximity to the target as distractors in the nine-item displays. 
used in the Öhman-feature condition. One observer was dropped from each condition because of false alarms greater than $10 \%$.

Apparatus and Stimuli. All stimuli were presented via a computer using VScope software (Enns, Ochs, \& Rensink, 1990; Enns \& Rensink, 1991). Observers were positioned against one end of a table, so that their eyes were approximately $60 \mathrm{~cm}$ from the monitor (no head restraint was used). An individual face stimulus subtended approximately $2.77^{\circ}$ wide $\times 3.15^{\circ}$ high. The entire nine-face array subtended $9.24^{\circ}$ by $10.76^{\circ}$ and was centered on a $0.92^{\circ} \times 0.92^{\circ}$ fixation cross. Within the array, the center of each face was separated from its neighbor by $2.74^{\circ}$ horizontally and by $3.04^{\circ}$ vertically, except that the exact position of an individual face within the $3 \times 3$ array was spatially jittered up to $0.22^{\circ}$ across trials. A single target face occurred randomly in one of the nine possible positions. The remaining eight locations were occupied by neutral faces. ${ }^{1}$ Examples of the spatial arrangement of stimuli can be seen in Figure 3.

Procedure. We used a go/no-go procedure. If the array contained a face different from the crowd of neutral faces, observers pressed the " 0 " key of a numeric keypad. If all of the faces in the array were neutral, observers refrained from responding. They knew that targetpresent and target-absent trials occurred at random, that the target would be at one of the nine possible locations, and that its position shifted randomly with each trial. Observers were told that their best performance could be achieved by focusing on the fixation cross as they initiated each trial. They were told not to anticipate the type of trial (target present or target absent) or where the target face might appear.

The stimulus crowds were previewed on the display monitor before practice and data collection. In common with other experiments, we did not describe the faces or refer to them as being happy, angry, or neutral (Gilboa-Schechtman et al., 1999; Hampton, Purcell, Bersine, Hansen, \& Hansen, 1989; Hansen \& Hansen, 1988; Öhman et al., 2001).

Trials were run in five blocks of 36 trials each. The first block was practice, and RTs from that block are not included in the data. Observers were not told of the proportion of target-to-nontarget trials ( $60 \%$ present: $40 \%$ absent). Observers were prompted by the computer to initiate a trial. A central fixation cross appeared for $705 \mathrm{msec}$. Its offset was followed by a white screen for $300 \mathrm{msec}$, followed by an array of faces. If the array contained a target face and the observer responded, the array offset, and the RT was recorded.
If the observer failed to respond, the array offset after $825 \mathrm{msec}$. If the crowd display did not contain a target, the stimulus array offset after $825 \mathrm{msec}$. The offset of the array was followed by an $855-\mathrm{msec}$ white screen, at which time the observer was cued to begin another trial. Observers were allowed to rest between blocks. Practice and data collection took about $20 \mathrm{~min}$.

\section{Results}

The mean RTs at each location in the stimulus array are shown for affect-neutral (Figure 4A) and Öhmanfeature (Figure 4B) faces. There was no systematic difference between Öhman-feature faces and neutral-feature/ affect-neutral target faces. There was a clear indication of a pseudo-ASE. The nonconforming stimuli (pseudoangry and angry) were responded to more quickly than were the conforming stimuli (pseudohappy and happy). For almost all stimuli, RTs were longest for targets at the first and third positions of a row, where acuity is poorest.

Feature organization (Öhman feature vs. affect neutral) was treated as between-subjects variable. Feature conformation (nonconforming [pseudoangry and angry] vs. conforming [pseudohappy and happy]) and position were within-subjects variables. Individual RTs were normalized by taking their common logarithm. Studentized scores with residuals whose absolute value was greater than 4 were dropped from the analysis. The interaction of feature conformation (conforming or nonconforming) with retinal position was a critical test of our prediction that a pseudo-ASE is strongest with stimuli presented furthest from the fovea.

Error rates were low in all experiments. For the affectneutral stimuli of the conforming/happy features gave $98.9 \%$ correct, and the nonconforming/angry features gave $98.5 \%$ correct ( $p=.67$ ) responses. For the Öhmanfeature faces, the conforming/happy features and the nonconforming/angry features gave, respectively, $98.8 \%$ and $99.4 \%$ correct $(p=.25)$ responses.

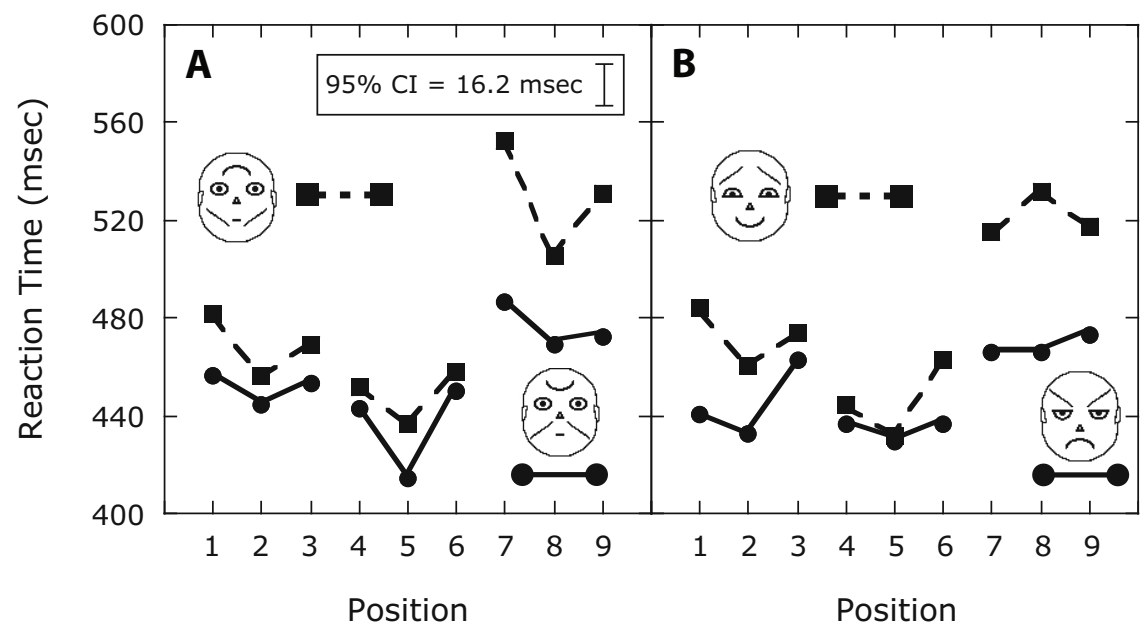

Figure 4. Experiment 2 data from affect-neutral faces (panel A) and from normal Öhmanfeature faces (panel B) for conforming/happy features and for nonconforming/angry features. Positions 1-3 are the top row, Positions 4-6 are the middle row, and Positions $7-9$ are the bottom row. Targets are shown. The $95 \%$ confidence interval is based on the $M S_{\mathrm{e}}$ for feature conformation. 
The variable of feature organization (Öhman-feature faces vs. affect-neutral faces) was not statistically significant $\left[F(1,30)=0.0394, M S_{\mathrm{e}}=0.0412, p=.84, \eta_{\mathrm{p}}^{2}=\right.$ $.001]$, but, as we expected, the main effect of feature conformation (angry/nonconforming vs. happy/conforming) was statistically significant $\left[F(1,30)=57.143, M S_{\mathrm{e}}=\right.$ $\left.0.00183, p \leq .0001, \eta_{\mathrm{p}}^{2}=.66\right]$, with faster search times for angry/nonconforming targets. Most important for our hypothesis is the finding that feature organization does not interact with feature conformation [angry/nonconforming vs. happy/conforming: $F(1,30)=0.17, M S_{\mathrm{e}}=0.0018$, $\left.p=.69, \eta_{\mathrm{p}}^{2}=.006\right]$. This interaction must be statistically significant if, in fact, judged affect predicts the ASE/ pseudo-ASE (Lundqvist \& Öhman, 2005; Öhman et al., 2001). This was not the case. Our affect-neutral stimuli produced as large an ASE/pseudo-ASE as did Öhman stimuli. Experiments $1 \mathrm{~A}$ and $1 \mathrm{~B}$ showed small differences ( 0.8 units) in affect ratings between our affect-neutral conforming and nonconforming stimuli, whereas that difference for Öhman nonconforming/angry and conforming/ happy stimuli was large (6.5 units). This contrast between affect ratings and the size of the ASE/pseudo-ASE provides a clear dissociation between how angry a face is rated and the RT data, just as our hypothesis requires.

Feature organization does not interact with any other variable, an additional indication that affect-neutral and Öhman stimuli are similar in their effect. The first-order interaction of feature organization $\times$ position gives $F(8,240)=0.91, M S_{\mathrm{e}}=0.001807, p=.51, \eta_{\mathrm{p}}^{2}=.03$, and the second-order interaction of feature organization $\times$ feature conformation $\times$ position gives $F(8,240)=$ $0.86, M S_{\mathrm{e}}=0.0012, p=.55, \eta_{\mathrm{p}}^{2}=.03$. Our affect-neutral stimuli produced results that are not different from those produced by Öhman-feature faces.

The magnitude of the ASE/pseudo-ASE differed as a function of retinal position. The main effect of position was statistically significant $\left[F(8,240)=21.53, M S_{\mathrm{e}}=\right.$ $\left.0.001807, p \leq .0001, \eta_{\mathrm{p}}^{2}=.42\right]$, and, as we predicted, so was the first-order interaction of feature conformation $X$ position $\left[F(8,240)=3.61, M S_{\mathrm{e}}=0.0012, p \leq .0006\right.$, $\left.\eta_{\mathrm{p}}^{2}=.11\right]$. Although it was not predicted by affect ratings, this interaction was consistent with the fact that the angry/nonconforming facial features are less influenced by position than are the conforming facial features (see Figure 4).

\section{EXPERIMENT 3 Four Versus Nine Stimuli}

In Experiment 2 we used only nine-item displays. In Experiment 3 we compare search with four-item displays with search with nine-item displays. The faces were identical with those of Experiment 2, although individual faces were separated from each other by a slightly larger space. Also, whereas Experiment 2 used 60\% target-present trials, Experiment 3 used 50\% target-present trials.

\section{Method}

Participants. Sixty undergraduate students volunteered to serve as observers as part of their introductory psychology course. Par- ticipants provided informed consent, as is required by the Institutional Review Board of Oakland University. We used 31 observers in the affect-neutral condition and an additional 29 observers in the Öhman-feature condition, from which 1 observer was dropped because of false alarms greater than $10 \%$.

Apparatus and Stimuli. All stimuli were presented via a computer using VScope software (Enns et al., 1990; Enns \& Rensink, 1991). Observers were positioned against one end of a table, so that their eyes were approximately $60 \mathrm{~cm}$ from the monitor (no head restraint was used). An individual face stimulus subtended approximately $3.1^{\circ}$ wide $\times 3.34^{\circ}$ high. The entire nine-face array subtended $12.46^{\circ}$ wide $\times 12.55^{\circ}$ high and was centered on a $0.92^{\circ} \times 0.92^{\circ}$ fixation cross. Within the array, the center of each face was separated from its neighbor $4.7^{\circ}$ horizontally and $4.6^{\circ}$ vertically, except that the exact position of an individual face within each $3 \times 3$ array was spatially jittered up to $0.22^{\circ}$ across trials. The spatial arrangement of nine-face arrays resembled that shown on the left side of Figure 3. Four-item displays resembled that shown on the right side of Figure $3 .^{2}$

Procedure. Experiment 3 used the same go/no-go procedure as was used in Experiment 2. Trials were run in four blocks of 72 trials each. This allowed for four trials per the 36 experiment conditions. Before data collection, two practice blocks of 15 trials each were run. Observers were not told of the proportion of target-present $(50 \%)$ to target-absent $(50 \%)$ trials. The trial sequence and timing was the same as in Experiment 2. Targets appeared pseudorandomly an equal number of times in each of the nine positions within the face array. Distractors clustered around the target in four-item arrays as closely as they did in nine-item arrays (see Figure 3).

\section{Results}

Error rates were very low in both Öhman and affectneutral stimuli. For the affect-neutral stimuli, the conforming/happy features were correctly reported on $97.94 \%$ of the trials, whereas the nonconforming/angry features were reported correctly $98.25 \%$ of the time ( $p=$ .43). The Öhman-feature faces of Experiment 3 gave $98.61 \%$ for the conforming/happy features and $98.96 \%$ for the nonconforming/angry features $(p=.41)$.

As in Experiment 2, the main effect of feature conformation [angry/nonconforming vs. happy/conforming, $\left.F(1,57)=198.27, M S_{\mathrm{e}}=0.002, p \leq .0001, \eta_{\mathrm{p}}^{2}=.78\right]$ was statistically significant, showing that stimuli that conform to the facial surround take longer to respond to than do stimuli that do not. The effect of feature organization (Öhman faces vs. affect-neutral faces) leaned toward statistical significance, with Öhman faces taking less time to respond to than did affect-neutral faces $[F(1,57)=2.51$, $\left.M S_{\mathrm{e}}=0.034, p=.12, \eta_{\mathrm{p}}^{2}=.042\right]$. If, as Öhman et al. (2001) argue, affect ratings predict the magnitude of the ASE/pseudo-ASE, there should be a strong interaction of feature conformation with feature organization with a much larger effect for the Öhman stimuli than for our affect-neutral stimuli. This is not supported by the data, because the interaction of feature conformation $\times$ feature organization $\left[F(8,456)=1.55, M S_{\mathrm{e}}=0.0014, p=.14\right.$, $\left.\eta_{\mathrm{p}}^{2}=.026\right]$ only leaned toward statistical significance. The ASE/pseudo-ASE was $36.5 \mathrm{msec}$ for the Öhman faces and $31.5 \mathrm{msec}$ for the affect-neutral faces. If affect judgment determined RT, then the interaction of feature conformation $\times$ feature organization would have been significant, with large differences between conforming and nonconforming faces for the Öhman-feature condition, but with little difference for the affect-neutral faces. 

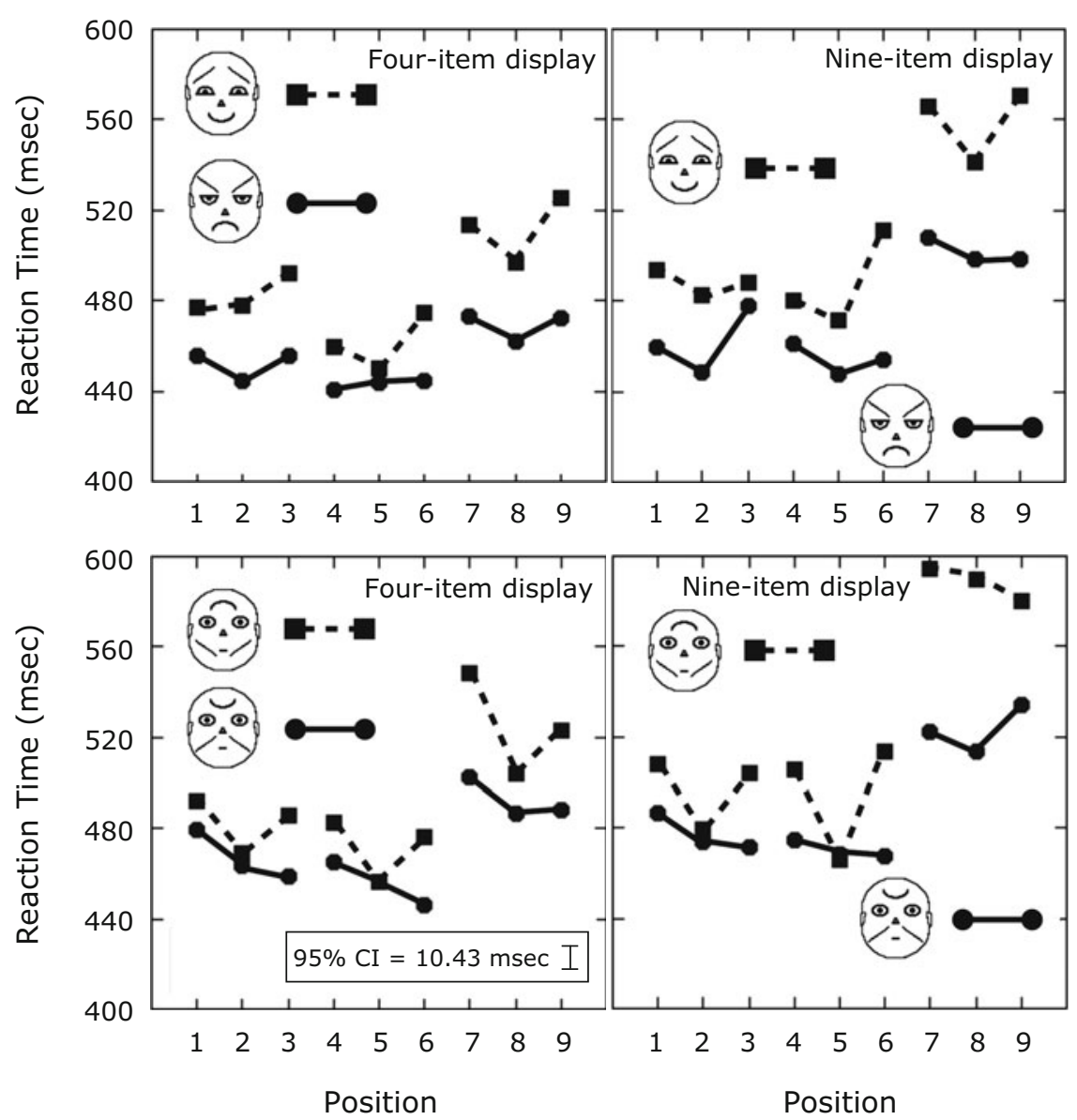

Figure 5. Data from the conforming/happy features and nonconforming/angry features of Experiment 3. The top panels display data for Öhman faces, and the bottom panels display data for our affect-neutral faces. In each panel, Positions 1-3 are the top row, Positions 4-6 are the middle row, and Positions 7-9 are the bottom row. The $95 \%$ confidence interval is based on the $M S_{\mathrm{e}}$ for feature conformation.

The statistically significant main effect of position $\left[F(8,456)=59.98, M S_{\mathrm{e}}=0.002, p \leq .0001, \eta_{\mathrm{p}}^{2}=.51\right]$ must be interpreted in light of the feature conformation $X$ position interaction $\left[F(8,456)=7.12, M S_{\mathrm{e}}=0.0014, p \leq\right.$ $\left..0001, \eta_{\mathrm{p}}^{2}=.11\right]$, as is shown in Figure 5. This interaction demonstrates that the conforming/happy stimuli are more difficult to locate than are nonconforming/angry stimuli when they are located farther and farther away from the fixation point, just as in Experiment 2. Although consistent with our feature-surround interaction hypothesis, this interaction is contrary to the Öhman affective activation hypothesis (Öhman et al., 2001, p. 393). The effect of position was constant across Öhman and affect-neutral faces, in that the feature organization $\times$ position interaction only leaned toward statistical significance $[F(8,456)=$ $\left.1.66, M S_{\mathrm{e}}=0.002, p=.11, \eta_{\mathrm{p}}^{2}=.028\right]$. The feature organization $\times$ feature conformation $\times$ position interaction showed a similar trend $\left[F(8,456)=1.55, M S_{\mathrm{e}}=0.00136\right.$, $\left.p=.14, \eta_{\mathrm{p}}^{2}=.026\right]$.

Number of stimuli (four vs. nine) was statistically significant $\left[F(1,57)=161.52, M S_{\mathrm{e}}=0.0014, p \leq .0001\right.$, $\left.\eta_{\mathrm{p}}^{2}=.74\right]$, with shorter RTs when targets were presented with three distractors than when they were presented with eight (Figure 8). The first-order interaction of number of stimuli $\times$ feature conformation was statistically significant $\left[F(1,57)=8.2, M S_{\mathrm{e}}=0.0012, p=.006, \eta_{\mathrm{p}}^{2}=.126\right]$. This interaction results from the faster search rates with nonconforming/angry stimuli $(3.6 \mathrm{msec} / \mathrm{item})$ than with conforming/happy stimuli ( $5.8 \mathrm{msec} /$ item $)$. These rates are consistent with efficient search for both target types. The slightly slower search for conforming targets may be due to the greater difficulty in determining their presence at some retinal positions (Figure 8 ). The interaction of number of stimuli $\times$ position is also statistically significant $\left[F(8,456)=7.5, M S_{\mathrm{e}}=0.0012, p \leq .0001, \eta_{\mathrm{p}}^{2}=.116\right]$. This interaction reflects the larger RT advantage for fouritem displays as compared with that for nine-item displays in the bottom row of the display. The average difference between four- and nine-item displays was $45.37 \mathrm{msec}$ in the bottom row of the display (Positions 7-9), whereas this difference averaged only $15 \mathrm{msec}$ for the other six positions (see Figure 5).

None of the other interactions involving number of stimuli were statistically significant. The first-order interaction 


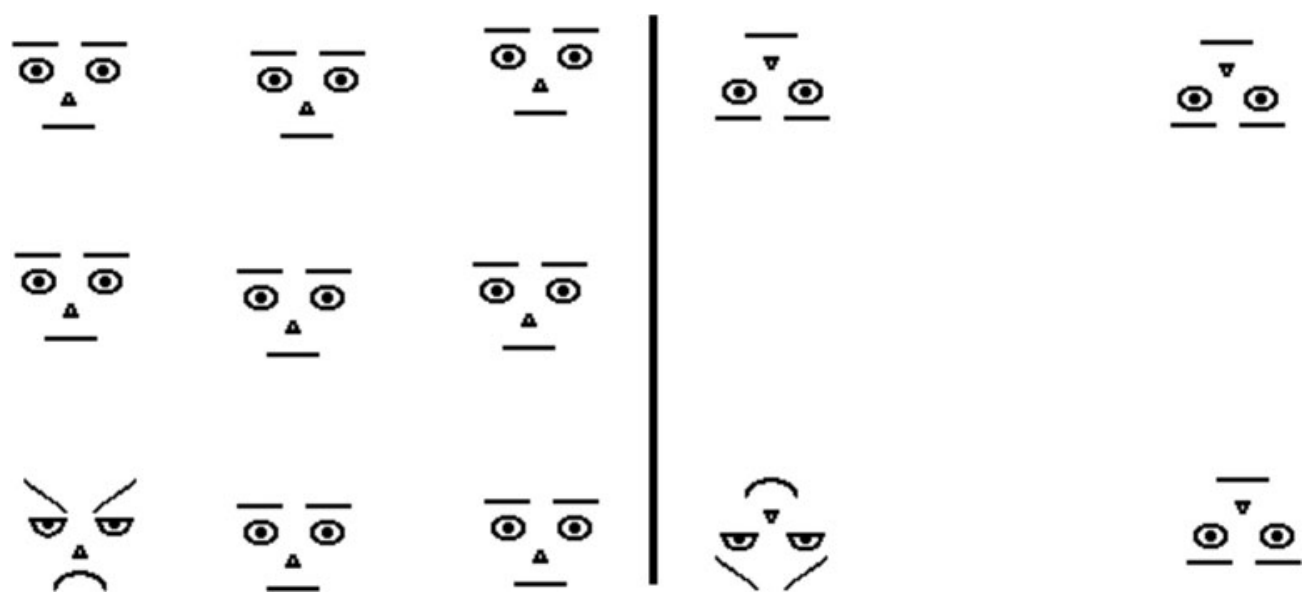

Figure 6. Examples of the stimuli used in Experiment 4. On the left is a nine-item display with an angry target. On the right is the $X$ configuration of an upside-down four-item display with a happy target. Not shown is the + configuration of a four-item display.

of feature organization (Öhman faces vs. affect-neutral) $\times$ number of stimuli yielded $F(1,57)=0.65, M S_{\mathrm{e}}=0.0014$, $p=.42, \eta_{\mathrm{p}}^{2}=.011$. The feature organization $\times$ feature conformation $\times$ number of stimuli interaction yielded $F(1,57)=0.77, M S_{\mathrm{e}}=0.0012, p=.38, \eta_{\mathrm{p}}^{2}=.013$, and the feature organization $\times$ position $\times$ number of stimuli interaction yielded $F(8,456)=0.68, M S_{\mathrm{e}}=0.0012, p=.71$, $\eta_{\mathrm{p}}^{2}=.012$. The feature conformation $\times$ position $\times$ number of stimuli interaction yielded $F(8,456)=1.31, M S_{\mathrm{e}}=$ $0.00146, p=.24, \eta_{\mathrm{p}}^{2}=.022$. The third-order interaction of feature organization $\times$ feature conformation $\times$ position $\times$ number of stimuli was not statistically significant $\left[F(8,456)=1.22, M S_{\mathrm{e}}=0.0011, p=.29, \eta_{\mathrm{p}}^{2}=.021\right]$.

In Experiments 2 and 3, the ASE/pseudo-ASE found with Öhman-feature faces was statistically indistinguishable from that found with our affect-neutral faces. Tipples et al. (2002) pointed out that the V-shaped eyebrow frown enhances the detectability of an angry face, relative to the inverted V-shaped eyebrow of the happy face. Larson, Aronoff, and Stearns (2007) make a similar argument. However, V-shaped eyebrow features produced opposite results when they were contained within our affect-neutral faces. The same enhanced detectability was obtained when the $\mathrm{V}$ is inverted (nonconforming), even though inversion makes it difficult to judge a face's emotion. We found that the nonconforming eyebrow feature enhances detectability, regardless of whether it was upright and V-shaped at the top of the Öhman-feature face or was an inverted V at the bottom of our affect-neutral stimuli. What is common to the two conditions - and what yields their faster detectability - are features that do not conform to their surrounds. Affect is largely irrelevant. ${ }^{3}$

\section{EXPERIMENT 4 \\ Normal and Inverted Surround-Absent Features}

There is a still more direct test for the presence of a pseudo-ASE. Remove the face's ovoid surround. The pseudo-ASE should disappear when the ovoid surround is removed, and why it disappears is an essential part of our narrative. Because the features of a happy face are no longer incorporated within the ovoid surround, the features of a happy face will be as legible as those of an angry face, and, therefore, a happy face will be located just as quickly as an angry face. Removing the facial surround also diminishes the effect of retinal position. With facial features no longer malformed by a facial surround, the position of a target face within an array becomes less important. Because removing the facial surround leaves affect ratings unchanged, Öhman features without surrounds should, if Öhman et al. (2001) are correct, produce a strong ASE.

\section{Method}

Participants. Sixty-nine students volunteered to participate as partial fulfillment of the requirements for their introductory psychology course. Thirty-six participants served in the right-side-up condition, and 33 served in the upside-down condition. One participant was dropped from the right-side-up condition, and 2 were dropped from the upside-down condition due to errors greater than $10 \%$. Participants provided informed consent, as is required by the Institutional Review Board of Oakland University.

Apparatus and Procedure. The apparatus and procedure were identical to those of Experiment 3 with three exceptions: The stimuli were the normal Öhman-feature stimuli with the facial surround removed. In one condition, normal upright versions were used, and, in the other, inverted versions were used (see Figure 6). Nine-item displays were spaced as in Experiment 3. However, four-item displays differed from those of Experiment 3. For half of the four-item displays, targets and distractors were presented in a + configuration at compass points of $0^{\circ}, 90^{\circ}, 180^{\circ}$, and $270^{\circ}$. For the other half, they were placed in an $\mathrm{X}$ configuration at $45^{\circ}, 135^{\circ}, 225^{\circ}$, and $315^{\circ}$ (see Figure 6 ). Item separation in the four-item displays ensured that individual features were seen as part of a coherent face and not as a jumble of unattached features, which might occur for the more closely spaced items in the nine-item display. ${ }^{4}$ With this spatial arrangement for the four-item displays, no target or distractor was presented at fixation. Only a distractor is presented at fixation in the nine-item displays.

\section{Results}

Stimulus orientation is a between-observers variable, whereas all other variables are within-observers. Error 

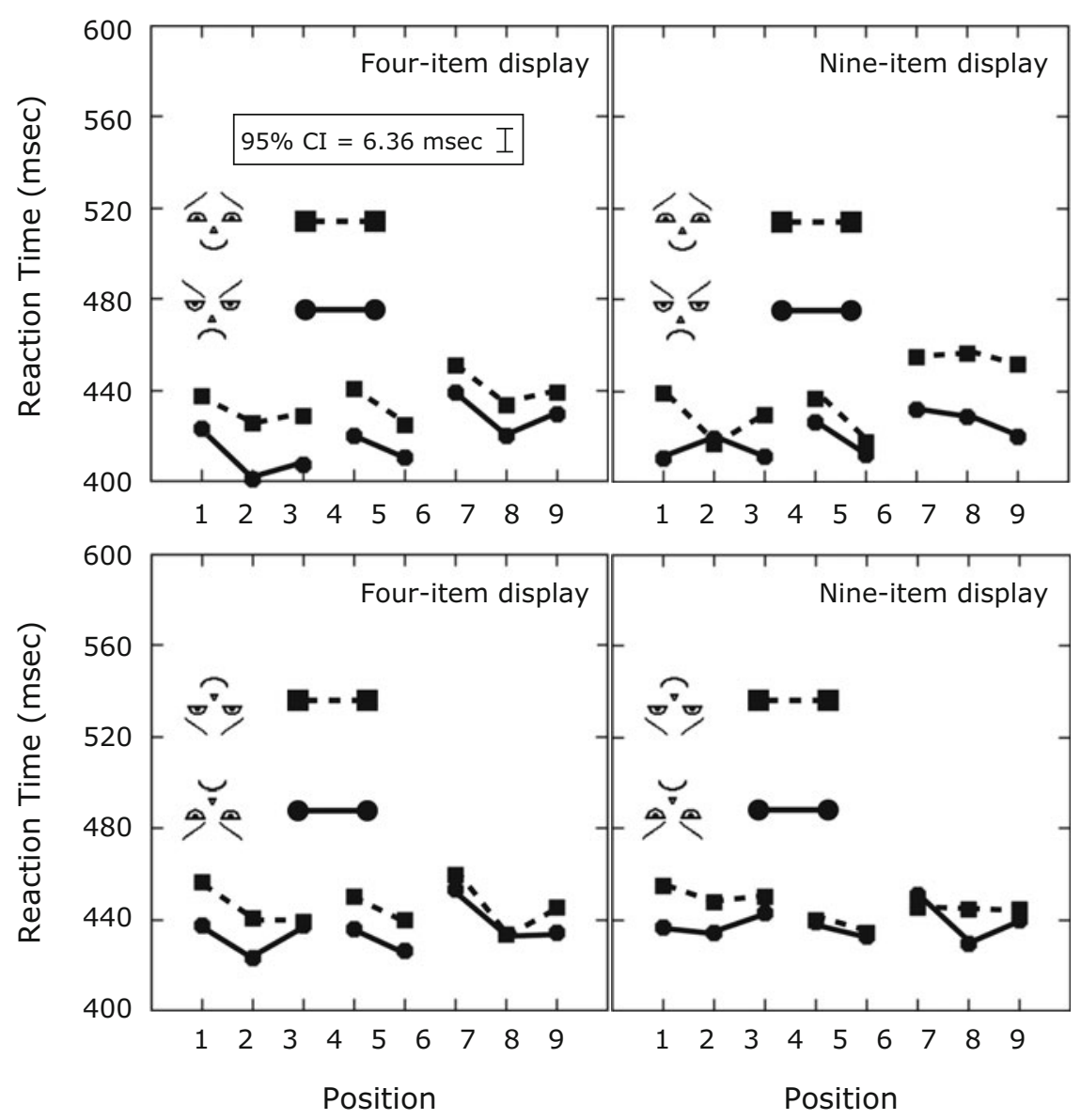

Figure 7. Data from the normal and inverted features of Experiment 4 are shown. Data from normal faces are in the top two panels, and those from inverted faces are in the bottom two panels. Data from four-item displays are on the left, and those from nine-item displays are on the right. Positions 1-3 are the top row, Positions 4-6 are the middle row, and Positions $7-9$ are the bottom row. The $\mathbf{9 5 \%}$ confidence interval is based on the $M S_{\mathrm{e}}$ for feature conformation.

rates are low. For the right-side-up stimuli of Experiment 4, the conforming/happy features gave $98.51 \%$ correct and the nonconforming/angry features gave $98.62 \%$ correct responses $(p=.78)$. For the inverted-feature faces of Experiment 4 , error rates were also low. The conforming/ happy features and the nonconforming/angry features gave, respectively, $98.66 \%$ and $99.16 \%$ correct responses $(p=.26)$.

Analysis of RTs and the ASE/pseudo-ASE revealed important differences from Experiments 2 and 3. Orientation (normal vs. upside-down) was not statistically significant $\left[F(1,64)=1.46, M S_{\mathrm{e}}=0.064, p=.23, \eta_{\mathrm{p}}^{2}=.022\right]$, although orientation interacted with other variables. As in Experiments 1 and 2, the main effect of feature conformation $\left[F(1,64)=73.102, M S_{\mathrm{e}}=0.001199, p \leq .0001\right.$, $\left.\eta_{\mathrm{p}}^{2}=.53\right]$ demonstrates a statistically significant ASE/ pseudo-ASE. We predicted that the ASE would disappear with elimination of the facial surround. Although that did not happen, removing the surround reduced the magnitude of the ASE by improving performance on the happy/ conforming features (see Figures 4, 5, and 7), just as we predicted. With angry/nonconforming features, surround removal produced a smaller improvement. Averaged across the surround-present conditions of Experiments 2 and 3 , there is a $31.5-\mathrm{msec}$ ASE/pseudo-ASE. Removing the facial surround decreased this to $17.76 \mathrm{msec}$. Inverting the surround-absent faces decreased the ASE/ pseudo-ASE by an additional $9.64 \mathrm{msec}$ to $8.12 \mathrm{msec}$. The fact that the ASE/pseudo-ASE is $9.64 \mathrm{msec}$ smaller for upside-down faces is supported by the feature conformation $\times$ orientation interaction $\left[F(1,64)=9.105, M S_{\mathrm{e}}=\right.$ $\left.0.077, p=.0037, \eta_{\mathrm{p}}^{2}=.13\right]$ and reinforces our work with surround-absent features modeled after those of Fox et al. (2000) and Purcell and Stewart (2006). As with the affect of feature conformation, removing the surround also reduced the effect of position $\left[F(7,448)=11.58, M S_{\mathrm{e}}=\right.$ $\left.0.00129, p \leq .0001, \eta_{\mathrm{p}}^{2}=.153\right]$ and eliminated the feature conformation $\times$ position interaction $[F(7,448)=0.79$, $\left.M S_{\mathrm{e}}=0.001, p=.59, \eta_{\mathrm{p}}^{2}=.012\right]$; see Figure 7.5 These effects related to retinal position also support our featuresurround interference hypothesis that interference from the surround is stronger farther away from fixation and 


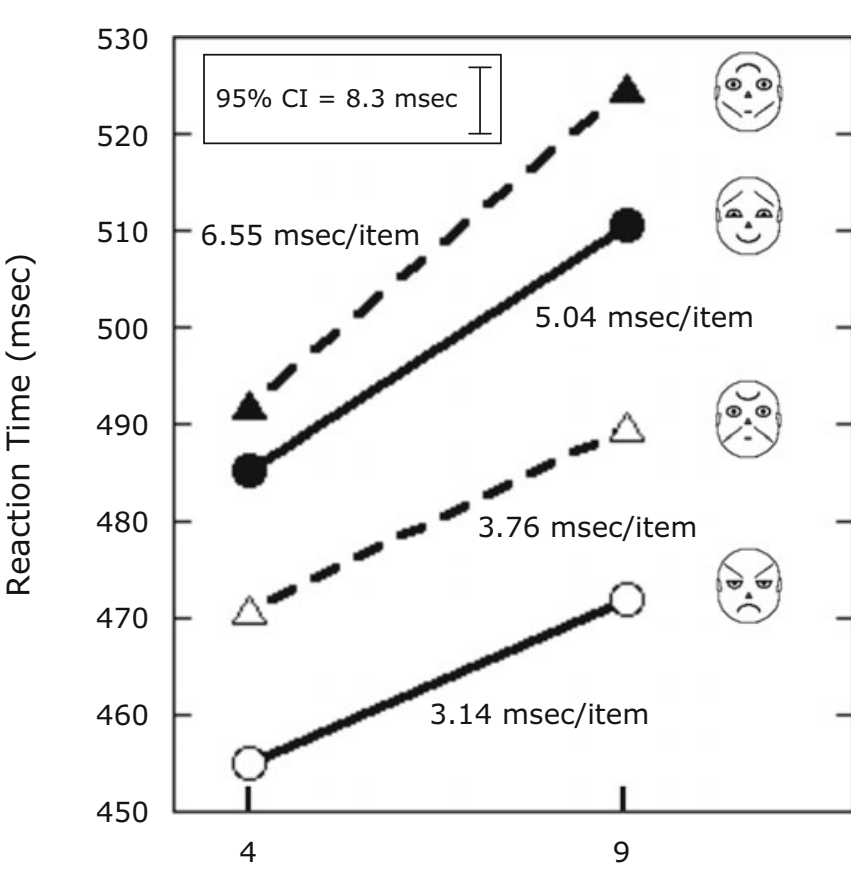

Number of Stimuli

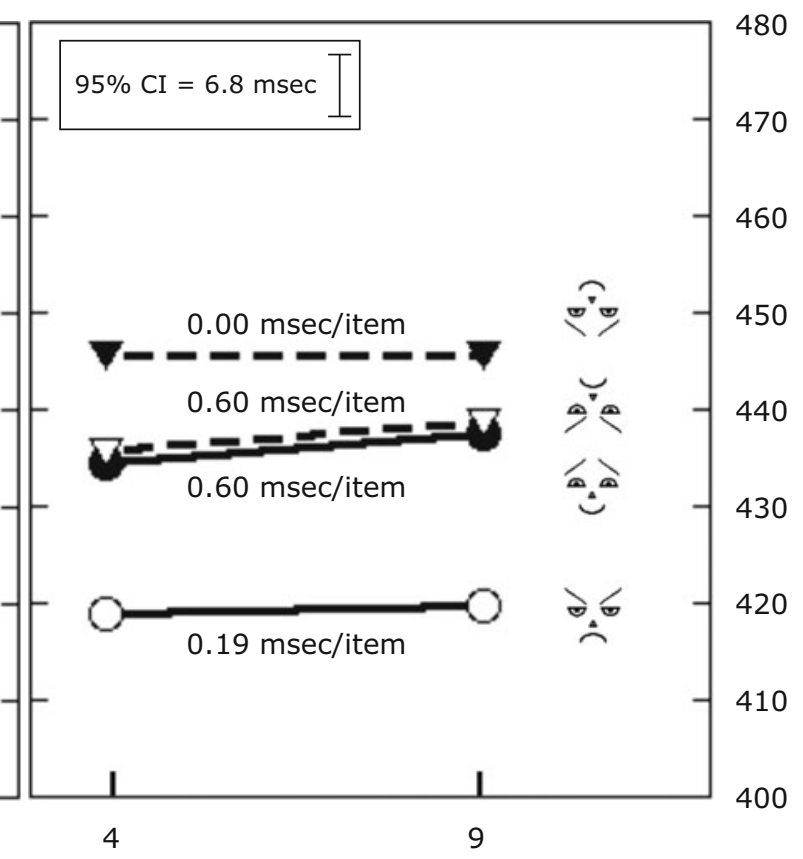

Number of Stimuli

Figure 8. Average slopes for Experiment 3 (left panel) and for Experiment 4 (right panel). To facilitate comparison between experiments, each panel has an RT range of $80 \mathrm{msec}$. Note that the slowest surround-absent RTs are faster than the fastest surround-present RTs. The $95 \%$ confidence intervals are based on the $M S_{\mathrm{e}}$ for number of stimuli.

that removing the surround eliminates this source of interference and makes stimuli more uniformly legible across retinal position. The orientation $\times$ position interaction was statistically significant $\left[F(7,448)=3.32, M S_{\mathrm{e}}=0.0012\right.$, $\left.p=.002, \eta_{\mathrm{p}}^{2}=.049\right]$, with smaller effects of position for inverted stimuli.

Unlike in Experiments 2 and 3, number of stimuli was not statistically significant $\left[F(1,64)=1.075, M S_{\mathrm{e}}=\right.$ $\left.0.0014, p=.30, \eta_{\mathrm{p}}^{2}=.017\right]$ and search slopes were nearly flat (Figure 8). The first-order interaction of orientation $X$ number of stimuli was not significant $[F(1,64)=0.034$, $\left.M S_{\mathrm{e}}=0.0014, p=.86, \eta_{\mathrm{p}}^{2}=.001\right]$, nor was the first-order interaction of feature conformation $\times$ number of stimuli $\left[F(1,64)=0.086, M S_{\mathrm{e}}=0.0009, p=.77, \eta_{\mathrm{p}}^{2}=.001\right]$; the first-order interaction of number of stimuli $\times$ position leaned toward statistical significance $[F(7,448)=1.93$, $\left.M S_{\mathrm{e}}=0.0009, p=.06, \eta_{\mathrm{p}}^{2}=.029\right]$. These nonsignificant first-order interactions must be qualified by the statistically significant second-order interaction of feature conformation $\times$ number of stimuli $\times$ position $[F(7,448)=$ $\left.2.14, M S_{\mathrm{e}}=0.0009, p=.038, \eta_{\mathrm{p}}^{2}=.032\right]$. This interaction appears to have been due to the ASE/pseudo-ASE having been relatively constant for six of the eight positions tested. However, this was not so for Positions 2 and 8. Position 2 showed a 17-msec larger ASE for fouritem displays than for nine-item displays, whereas Position 8 showed the opposite pattern, with a 15 -msec larger ASE for the nine-item display. The second-order interactions of orientation $\times$ feature conformation $\times$ number of stimuli $\left[F(1,64)=0.77, M S_{\mathrm{e}}=0.0009, p=.38, \eta_{\mathrm{p}}^{2}=\right.$
$.012]$ and orientation $\times$ feature conformation $\times$ position $\left[F(7,448)=0.80, M S_{\mathrm{e}}=0.001, p=.59, \eta_{\mathrm{p}}^{2}=.012\right]$ were not statistically significant. The third-order interactions of orientation $\times$ number of stimuli $\times$ position $[F(7,448)=$ $\left.0.73, M S_{\mathrm{e}}=0.0009, p=.65, \eta_{\mathrm{p}}^{2}=.011\right]$ and orientation $\times$ feature conformation $\times$ number of stimuli $\times$ position $\left[F(7,448)=1.28, M S_{\mathrm{e}}=0.0009, p=.256, \eta_{\mathrm{p}}^{2}=.02\right]$ were not statistically significant.

\section{Discussion}

The results of Experiment 4 differed from those of Experiments 2 and 3 in three important ways. Without a surround, the ASE was greatly reduced, even though Experiment 1 showed that the surround-absent features themselves were rated just as angry and happy as were faces with surrounds. Important for our hypothesis, removing the surround yielded a greater improvement in performance for the conforming/happy features than for the nonconforming/angry features. As can be seen by comparing Figures 4 and 5 with Figure 7, the effect of feature conformation is reduced, as is the effect of position, and there was no longer an interaction between feature conformation and position. In other words, the magnitude of the surround-absent ASE/pseudo-ASE was no longer dependent on target position as it was for faces with surrounds.

When the facial surround was absent, there was a smaller ASE $(17.76 \mathrm{msec})$ than that found when the surround was present $(31.5 \mathrm{msec})$. To determine the extent to which this reduced ASE is due to non-affect-related fac- 
tors, we inverted the surround-absent stimuli. Should face inversion have had no effect on the magnitude of the ASE, we would have concluded that the surround-absent ASE is due only to low-level features. However, the low-level feature effects of the inverted faces produced a smaller ASE/pseudo-ASE $(8.12 \mathrm{msec})$. The difference between this and the ASE/pseudo-ASE found with right-side-up features suggests the possibility of a 9.64-msec true ASE with surround-absent faces. Our advice is that investigations of the schematic face ASE use surround-absent features coupled with an upside-down control to assess the contribution of nonemotional factors to the effect.

\section{GENERAL DISCUSSION}

Öhman et al. (2001) argued that the angrier a face is rated, the faster an observer will respond to that face when it is used in a visual search task. In our Experiments 2 and 3, schematic faces, which were rated 6.53 units more angry than happy faces, produced an average ASE of 33 msec. However, our affect-neutral stimuli with nonconforming features were rated only slightly angrier than the conforming stimuli (Experiment 1A, 5.8 vs. 5.0; Experiment 1B, 6.26 vs. 5.39). These stimuli still produced a pseudo-ASE of $29 \mathrm{msec}$ - a result that is $4 \mathrm{msec}$ smaller and not statistically different from that produced with Öhman stimuli. An experiment using many more observers could find that this residual 4-msec difference is statistically significant. Nonetheless, such a circumspect interpretation of the data does not alter the fact that eliminating the feature-surround interaction results in statistically significant faster responses for stimuli with conforming/happy features.

There are also other troublesome anomalies for experiments on emotion and visual search. Variation in the size of the ASE/pseudo-ASE with retinal position is not predicted by affect ratings. Nor do affect ratings predict the reduction in the size of the pseudo-ASE that occurs when stimuli are presented without a facial surround. Even with large differences in affect ratings (6.26 units), the surround-absent stimuli produce an ASE/pseudo-ASE that we estimate as being only $9.64 \mathrm{msec}$, and the effect across retinal position is much smaller than with Öhman stimuli. Whatever a person's view of the ASE effect might be, the Öhman stimuli are fraught with the kind of lowlevel visual artifacts they were meant to avoid, leaving the existence of an ASE an open question.

It could still be argued that there is an ASE with surround-present Öhman stimuli, but the evidence is ambiguous. If the results are due to an ASE, it is curious that a similar ASE is produced with our almost affect-neutral stimuli.

Even the origin of the ASE and pseudo-ASE remains an open question. The ASE is often seen as the result of evolutionarily selected means of rapidly detecting a threatening individual (Eastwood et al., 2001; Fox et al., 2000; Öhman et al., 2001). There are equally plausible alternative explanations, however. The schematic face effect may to be due to low-level features that are unrelated to facial affect, but that give an advantage to angry features (Calvo \& Nummenmaa, 2008; Coelho et al., 2010). Alternatively, as we propose, the effect can be due to low-level features that give an absolute disadvantage to the happy face (Purcell \& Stewart, 2005, 2006). All the nonaffect, low-level feature models for the pseudo-ASE provide that a facial surround is necessary to obtain the effect. Two of the nonaffect models postulate that a pseudo-ASE is due to an absolute advantage for angry features that comes about because of an interaction between the outward pointing eyebrow and mouth features with the facial surround (Calvo \& Nummenmaa, 2008; Coelho et al., 2010). Calvo and Nummenmaa argue that the facial surround renders the angry features as being more distinctive, relative to happy and neutral features. Coelho et al. demonstrate, with simple geometric shapes, that the surround interacts with the outward pointing eyebrows and mouths of an angry face to yield easily detected T-junctions. Our alternative explanation is that the ASE/pseudo-ASE is the result of a destructive interaction between the facial surround and conforming/happy features. This destructive action makes it more difficult to identify a happy face. None of these low-level feature explanations require assumptions about rapid processing of facial affect.

\section{AUTHOR NOTE}

Correspondence concerning this article should be addressed to D. G. Purcell, Psychology Department, Oakland University, Rochester, MI 48309 (e-mail: purcell@oakland.edu).

\section{REFERENCES}

Ashwin, C., Wheelwright, S., \& Baron-Cohen, S. (2006). Finding a face in the crowd: Testing the anger superiority effect in Asperger syndrome. Brain \& Cognition, 61, 78-95. doi:10.1016/j.bandc.2005 .12 .008

Boucher, J. D., \& Carlson, G. E. (1980). Recognition of facial expression in three cultures. Journal of Cross-Cultural Psychology, 11, 263-280. doi:10.1177/0022022180113003

Calvo, M. G., \& NummenmaA, L. (2008). Detection of emotional faces: Salient physical features guide effective visual search. Journal of Experimental Psychology: General, 137, 471-494. doi:10.1037/ a0012771

Coelho, C. M., Cloete, S., \& Wallis, G. (2010). The face-in-thecrowd effect: When angry faces are just cross(es). Journal of Vision, 10(1, Art. 7), 1-14. doi:10.1167/10.1.7

Eastwood, J. D., Smilek, D., \& Merikle, P. M. (2001). Differential attentional guidance by unattended faces expressing positive and negative emotion. Perception \& Psychophysics, 63, 1004-1013.

Eastwood, J. D., SmileK, D., \& Merikle, P. M. (2003). Negative facial expression captures attention and disrupts performance. Perception \& Psychophysics, 65, 352-358.

Enns, J. T., Ochs, E. P., \& Rensink, R. A. (1990). VSearch: Macintosh software for experiments in visual search. Behavior Research Methods, Instruments, \& Computers, 22, 118-122.

EnNs, J. T., \& REnsink, R. A. (1991). VSearch Color: Full-color visual search experiments on the Macintosh II. Behavior Research Methods, Instruments, \& Computers, 23, 265-272.

Fox, E., Lester, V., Russo, R., Bowles, R. J., Pichler, A., \& DutTON, K. (2000). Facial expressions of emotion: Are angry faces detected more efficiently? Cognition \& Emotion, 14, 61-92.

Gilboa-Schechtman, E., FoA, E. B., \& Amir, N. (1999). Attentional biases for facial expressions in social phobia: The face-in-thecrowd paradigm. Cognition \& Emotion, 13, 305-318. doi:10.1080/ 026999399379294

Hahn, S., Carlson, C., Singer, S., \& Gronlund, S. D. (2006). Aging and visual search: Automatic and controlled attentional bias to threat faces. Acta Psychologica, 123, 312-336. doi:10.1016/j.actpsy .2006.01.008 
Hampton, C., Purcell, D. G., Bersine, L., Hansen, C. H., \& HanSEN, R. D. (1989). Probing "pop-out": Another look at the face-in-thecrowd effect. Bulletin of the Psychonomic Society, 27, 563-566.

Hansen, C. H., \& Hansen, R. D. (1988). Finding the face in the crowd: An anger superiority effect. Journal of Personality \& Social Psychology, 54, 917-924. doi:10.1037/0022-3514.54.6.917

Harrison, D. W., Gorelczenko, P. M., \& Cook, J. (1990). Sex differences in the functional asymmetry for facial affect perception. International Journal of Neuroscience, 52, 11-16. doi:10.3109/00207459008994238

Horstmann, G. (2007). Preattentive face processing: What do visual search experiments with schematic faces tell us? Visual Cognition, 15, 799-833. doi:10.1080/13506280600892798

HorstmanN, G., \& BeCKER, S. I. (2008). Attentional effects of negative faces: Top-down contingent or involuntary? Perception \& Psychophysics, 70, 1416-1434. doi:10.3758/PP.70.8.1416

Juth, P., Lundevist, D., Karlsson, A., \& Öhman, A. (2005). Looking for foes and friends: Perceptual and emotional factors when finding a face in the crowd. Emotion, 5, 379-395. doi:10.1037/1528 $-3542.5 .4 .379$

KIROUAC, G., \& DorÉ, F. Y. (1984). Judgment of facial expressions of emotion as a function of exposure time. Perceptual \& Motor Skills, 59, 147-150.

Kirouac, G., \& Doré, F. Y. (1985). Accuracy of the judgment of facial expression of emotions as a function of sex and level of education. Journal of Nonverbal Behavior, 9, 3-7. doi:10.1007/BF00987555

Larson, C. L., Aronoff, J., \& Stearns, J. J. (2007). The shape of threat: Simple geometric forms evoke rapid and sustained capture of attention. Emotion, 7, 526-534. doi:10.1037/1528-3542.7.3.526

Leppänen, J. K., Tenhunen, M., \& Hietanen, J. K. (2003). Faster choice-reaction times to positive than to negative facial expressions. Journal of Psychophysiology, 17, 113-123. doi:10-1027//0269 $-8803.17 .3 .113$

LundQvist, D., Esteves, F., \& ÖHMAN, A. (1999). The face of wrath: Critical features for conveying facial threat. Cognition \& Emotion, 13, 691-711. doi:10.1080/026999399379041

LundQvist, D., \& ÖHMan, A. (2005). Emotion regulates attention: The relation between facial configurations, facial emotion, and visual attention. Visual Cognition, 12, 51-84. doi:10.1080/13506280444000085

Mandal, M. K., \& Palchoudhury, S. (1985). Perceptual skill in decoding facial affect. Perceptual \& Motor Skills, 60, 96-98.

Mather, M., \& KNight, M. R. (2006). Angry faces get noticed quickly: Threat detection is not impaired among older adults. Journals of Gerontology, 61B, P54-P57.

McANDREW, F. T. (1986). A cross-cultural study of recognition thresholds for facial expressions of emotion. Journal of Cross-Cultural Psychology, 17, 211-224. doi:10.1177/0022002186017002005

OBrecht, N. A., \& Purcell, D. G. (2005, May). Anger inferiority effect demonstrated in both crowd and single face presentations. Poster presented at the 17th Annual Convention of the American Psychological Society, Los Angeles, CA.

Öhman, A., Lundevist, D., \& Esteves, F. (2001). The face in the crowd revisited: A threat advantage with schematic stimuli. Journal of Personality \& Social Psychology, 80, 381-396. doi:10.1037/0022 $-3514.80 .3 .381$

Pizzamiglio, L., Zoccolotti, P., Mammucari, A., \& Cesaroni, R. (1983). The independence of face identity and facial expression recognition mechanisms: Relationship to sex and cognitive style. Brain \& Cognition, 2, 176-188. doi:10.1016/0278-2626(83)90007-6

Purcell, D. G., \& Stewart, A. L. (2002, November). The face in the crowd: Yet another confound. Poster presented at the 43rd Annual Meeting of the Psychonomic Society, Kansas City, MO.

Purcell, D. G., \& Stewart, A. L. (2003, November). An anger inferiority effect with schematic faces. Poster presented at the 44th Annual Meeting of the Psychonomic Society, Vancouver.

Purcell, D. G., \& Stewart, A. L. (2005, November). Anger superiority: Effects of facial surround and similarity of targets and distractors. Poster presented at the 46th Annual Meeting of the Psychonomic Society, Toronto.

Purcell, D. G., \& Stewart, A. L. (2006, May). The anger superior- ity effect: Confounds with schematic stimuli. Poster presented at the 18th Annual Meeting of the Association for Psychological Science, New York.

Purcell, D. G., Stewart, A. L., \& Skov, R. B. (1996). It takes a confounded face to pop out of a crowd. Perception, 25, 1091-1108. doi:10.1068/p251091

Purcell, D. G., Stewart, A. L., \& Skov, R. B. (1998). Interference effects of facial affect. In R. R. Hoffman, M. F. Sherrick, \& J. S. Warm (Eds.), Viewing psychology as a whole: The integrative science of William N. Dember (pp. 433-447). Washington, DC: American Psychological Association.

Rousselet, G. A., Husk, J. S., Bennett, P. J., \& Sekuler, A. B. (2005). Spatial scaling factors explain eccentricity effects on face ERPs. Journal of Vision, 5, 755-763. doi:10.1167/8.12.3

RufFMAn, T., NG, M., \& JENKIN, T. (2009). Older adults respond quickly to angry faces despite labeling difficulty. Journals of Gerontology, 64B, P171-P179. doi:10.1093/geronb/gbn035

Schubö, A., Gendolla, G. H. E., Meinecke, C., \& Abele, A. E. (2006). Detecting emotional faces and features in a visual search paradigm: Are faces special? Emotion, 6, 246-256. doi:10.1037/1528 $-3542.6 .2 .246$

Shimoda, K., Argyle, M., \& Ricci-Bitti, P. E. (1978). The intercultural recognition of emotional expressions by three national racial groups: English, Italian, and Japanese. European Journal of Social Psychology, 8, 169-179. doi:10.1002/ejsp.2420080203

Srivastava, P., \& Mandal, M. K. (1990). Proximal spacing to facial affect expressions in schizophrenia. Comprehensive Psychiatry, 31, $119-124$.

Stalans, L., \& Wedding, D. (1985). Superiority of the left hemisphere in the recognition of emotional faces. International Journal of Neuroscience, 25, 219-223.

Tipples, J., Atkinson, A. P., \& Young, A. W. (2002). The eyebrow frown: A salient social signal. Emotion, 2, 288-296. doi:10.1037/1528 $-3542.2 .3 .288$

Wagner, H. L., MacDonald, C. J., \& Manstead, A. S. R. (1986). Communication of individual emotions by spontaneous facial expressions. Journal of Personality \& Social Psychology, 50, 737-743.

WATERs, A. M., \& LiPP, O. V. (2008). Visual search for emotional faces in children. Cognition \& Emotion, 22, 1306-1326. doi:10.1080/ 02699930701755530

Williams, M. A., \& Mattingley, J. B. (2006). Do angry men get noticed? Current Biology, 16, R402-R404.

\section{NOTES}

1. To compensate for retinal position, stimuli above and below fixation would have to be increased in size by a factor of 2.47. Stimuli directly left and right of fixation would have to be increased in size by a factor of 2.26, whereas stimuli on the corners of the display would have to be increased by a factor of 3.48 .

2. To compensate for retinal position, stimuli above and below fixation would have to be increased in size by a factor of 2.71 . Stimuli directly left and right of fixation would have to be increased in size by a factor of 2.7 , whereas stimuli on the corners of the display would have to be increased by a factor of 3.83 .

3. Our findings suggest that the use of schematic faces to investigate face perception of people with affect disorders may greatly overestimate the magnitude of the ASE for those individuals (e.g., Ashwin, Wheelwright, \& Baron-Cohen, 2006; Hahn, Carlson, Singer, \& Gronlund, 2006; Mather \& Knight, 2006; Ruffman, Ng, \& Jenkin, 2009; Waters \& Lipp, 2008).

4. This was done because of concerns of an anonymous reviewer that surround-absent faces might appear as a jumble of features.

5. Although we found a reduced effect of feature conformation when surrounds are removed, Schubö et al. (2006) reported no effect of feature conformation when surrounds were removed.

(Manuscript received November 30, 2008; revision accepted for publication June 8, 2010.) 